\title{
Total replacement of dietary fish oil with alternative lipid sources in a practical diet for mandarin fish, Siniperca scherzeri, juveniles
}

\author{
Zohreh Sankian', Sanaz Khosravi ${ }^{1}$, Yi-Oh Kim² and Sang-Min Lee ${ }^{1 *}$
}

\begin{abstract}
A 12-week feeding trial was designed to evaluate the effect of total replacement of fish oil (FO) with terrestrial alternative oils on growth, feed utilization, body composition, hematological parameters, and fillet fatty acid profile of mandarin fish juveniles. Four iso-nitrogenous (56\% crude protein) and iso-lipidic (13\% crude lipid) practical diets were formulated. A control diet contained $6 \% \mathrm{FO}$ and three other experimental diets were prepared by replacing FO with linseed oil, soybean oil, and lard (designed as FO, LO, SO, and lard, respectively). Each diet was randomly allocated to triplicate groups of 25 fish $(1.8 \pm 0.03 \mathrm{~g} /$ fish $)$ in a circular tank. Complete replacement of FO by three tested alternative oils had no remarkable impact on growth performance, feed utilization efficiency, and morphological and hematological parameters of juvenile mandarin fish. However, daily feed intake was found to be significantly higher for fish fed the SO diet compared with those fed the FO and LO diets. Fish fed LO and SO diets exhibited significantly higher levels of the whole body lipid compared to fish fed diet containing FO. Fillet fatty acid composition reflected dietary fatty acid profile. The highest level of a-linolenic acid, linoleic acid, and oleic acid was observed in fish fillet fed LO, SO, and lard, respectively. Although the eicosapentaenoic acid level of fish fillet fed diet FO was higher than other treatments, no significant difference was found in docosahexaenoic acid content among all dietary groups. The results of the present study clearly demonstrate that the complete replacement of FO in mandarin fish diets is achievable. These findings are useful in dietary formulation to reduce feed costs without compromising mandarin fish growth.
\end{abstract}

Keywords: Growth performance, Feed utilization efficiency, Fillet fatty acid composition, Fish oil replacement, Mandarin fish, Siniperca scherzeri

\section{Background}

Feed ingredients of marine origin such as fish meal (FM) and fish oil (FO) have been extensively used as the main protein and lipid sources in the aquafeeds. Fish oil is particularly popular in aquafeed industry because of its high proportions of $n-3$ long-chain polyunsaturated fatty acids (LC-PUFA) that play an important role in supporting normal growth, health, and nutritional quality of farmed aquatic animals (Turchini et al. 2011b). However, it is clearly evident that the aquafeed-manufacturing industry cannot continue to rely on this highly palatable and nutritious marine ingredient. Indeed, the sustainability

\footnotetext{
* Correspondence: smlee@gwnu.ac.kr

${ }^{1}$ Department of Marine Bioscience and Technology, Gangneung-Wonju

National University, Gangneung 25457, South Korea

Full list of author information is available at the end of the article
}

issues and rising costs linked with FO have exerted and continue to exert substantial pressure on global aquafeed sector to find economically viable and environmentally sustainable substitutions. In this regard, terrestrial oils, particularly vegetable oils, have been considered as the prime candidates for FO replacement in aquafeeds due to their high availability and relatively lower prices (Turchini et al. 2011b). In comparison to FO, however, oils of terrestrial origin are typically rich in $\mathrm{C}_{18}$ fatty acids, mainly linoleic (LA, 18:2n-6), $\alpha$-linolenic (ALA, 18:3n-3), and oleic (OA, 18:1n-9) acids, but lack or have a very limited content of the n-3 LC-PUFA, such as eicosapentaenoic (EPA, 20:5-3) and docosahexaenoic (DHA, 22:6n-3) acids, which are regarded as undesirable nutritional properties (Bureau and Meeker 2011; Nasopoulou and Zabetakis 2012). Consequently, numerous studies have investigated the efficacy

(c) The Author(s). 2019 Open Access This article is distributed under the terms of the Creative Commons Attribution 4.0 International License (http://creativecommons.org/licenses/by/4.0/), which permits unrestricted use, distribution, and reproduction in any medium, provided you give appropriate credit to the original author(s) and the source, provide a link to the Creative Commons license, and indicate if changes were made. The Creative Commons Public Domain Dedication waiver (http://creativecommons.org/publicdomain/zero/1.0/) applies to the data made available in this article, unless otherwise stated. 
of various oils of terrestrial origin in feeds for cultured fish. Overall, the literature evidence suggests that most alternative oil sources are able to replace FO to some extent depending upon the species studied and also the type and fatty acid content of the alternative oil used (Turchini et al. 2011b). It is also now generally recognized that partial or full substitution of FO is more feasible for freshwater fish than marine species which apparently lack the ability to desaturate and elongate $\mathrm{C}_{18}$ PUFA and therefore are very prone to $\mathrm{n}$-3 LC-PUFA deficiency (Tocher 2010). Indeed, a review of previous experiments with freshwater species such as Murray cod, Maccullochella peelii peelii (Turchini et al. 2011a); pikeperch, Sander lucioperca (L.) (Kowalska et al. 2012); snakehead, Channa striatus (Aliyu-Paiko and Hashim 2012); darkbarbel catfish, Pelteobagrus vachelli (Jiang et al. 2013); Nile tilapia, Oreochromis niloticus (Peng et al. 2015; Apraku et al. 2017); gibel carp, Carassius auratus gibelio (Zhou et al. 2016); silver catfish, Rhamdia quelen (Lazzari et al. 2016); and rainbow trout, Oncorhynchus mykiss (Gause and Trushenski 2013; Ylldız et al. 2018); has shown that it is possible to replace FO by single or a mixture of terrestrial oils (both vegetable and animal oils) without compromising growth or feed efficiencies.

Mandarin fish, Siniperca scherzeri, is a strict freshwater piscivore mainly found throughout East China, Korea, and Northern Vietnam (Zhou et al. 1988; Li 1991). The growing interest in mandarin fish culture has been triggered by increasing demand on its shrinking wild stock (Wu et al. 1997; Chu et al. 2013). Yet, so far, there is relatively little scientific information available concerning mandarin fish nutrition (Zhang et al. 2009; Lee et al. 2012; Sankian et al. 2017, 2018, 2019), and its commercial production still relies on expensive live prey. Hence, one of the most important steps in developing and implementing a profitable and sustainable culture practice for this species is to formulate a nutritionally balanced and cost-effective commercial feed. A recent feeding trial with mandarin fish juveniles, of $<9 \mathrm{~g}$, in our laboratory demonstrated that a diet containing 55\% crude protein and 14\% crude lipid yielded the best feeding and growth performance (Sankian et al. 2017). However, there is no information available on the use of alternative lipid source in a practical diet of this species. Therefore, the overall aim of this study was to investigate the possible effects of total substitution of dietary FO with alternative lipid sources including linseed oil, soybean oil, or lard on mandarin fish juveniles in terms of growth performance, efficiency of feed utilization, whole body proximate composition, biochemical indices, and fillet fatty acid profile. It is likely that the main findings in this study could be useful in formulating a cost-effective practical diet for this emerging species of increasing interest in the South Korean freshwater aquaculture sector.

\section{Methods}

\section{Experimental diets}

Fatty acid composition of the tested oil sources are shown in Table 1 and the formulation and proximate composition of the experimental diets are presented in Table 2. Four iso-nitrogenous (approximately 56\% crude protein) and iso-lipidic (approximately 13\% crude lipid experimental diets, varying only in the added lipid source) were formulated using anchovy FM as the main source of protein. In all the experimental diets, $\sim 6 \%$ lipid was provided from the residual oil in the FM and other dietary ingredients, while the other $6 \%$ lipid was achieved through separate addition of four different oil sources including fish oil (FO), linseed oil (LO), soybean oil (SO), and lard to the diet, and the resultant experimental diets were named accordingly. For preparing each experimental diet, all the dry ingredients were thoroughly mixed with oil and distilled water to form a sticky dough, which was then passed through a mincer (SMC-32, SL Co., Incheon, South Korea) to produce 3.0-mm-diameter feed strands. The moist feed strands were then chopped into pellets of a desired length (approximately 15 to $18 \mathrm{~mm}$ ), dried on wire racks at $25^{\circ} \mathrm{C}$ in a forced air oven overnight, and kept frozen at $-20^{\circ} \mathrm{C}$ until used. A pilot study in our laboratory has shown that the size, shape, and texture of the feed pellets play an important role in the acceptance of artificial diets by mandarin fish which is well known for its very unique food preference (Liang et al. 1998; Li et al. 2017). The fish was found to be most attracted to the 15 to 18 -mm-long moist pellets, which contained more than $30 \%$ moisture.

Table 1 Major fatty acid composition (\% total fatty acids) of the tested oil sources

\begin{tabular}{|c|c|c|c|c|}
\hline & Oil sc & & & \\
\hline & $\mathrm{FO}$ & LO & $\mathrm{SO}$ & Lard \\
\hline $14: 0$ & 9.8 & 0.1 & 0.1 & 2.1 \\
\hline $16: 0$ & 19.6 & 5.6 & 11.9 & 22.6 \\
\hline $18: 0$ & 3.9 & 3.6 & 4.1 & 12.2 \\
\hline $16: 1 n-7$ & 10.7 & 0.1 & 0.1 & 2.1 \\
\hline $18: 1 n-9(O A)^{1}$ & 7.0 & 16.0 & 26.1 & 43.3 \\
\hline $18: 2 n-6(L A)^{2}$ & 1.5 & 15.5 & 48.2 & 11.2 \\
\hline $18: 3 n-3(\text { ALA })^{3}$ & 0.6 & 48.7 & 5.8 & 0.1 \\
\hline $20: 4 n-6$ & - & - & - & - \\
\hline $20: 5 n-3(E P A)^{4}$ & 15.4 & - & - & - \\
\hline $22: 5 n-3$ & - & - & - & - \\
\hline $22: 6 n-3(\mathrm{DHA})^{5}$ & 5.7 & - & - & - \\
\hline
\end{tabular}

FO fish oil, $L O$ linseed oil, SO soybean oil

'Oleic acid

${ }^{2}$ Linoleic acid

${ }^{3} \mathrm{a}$-Linolenic acid

${ }^{4}$ Eicosapentaenoic acid

${ }^{5}$ Decosahexaenoic acid 
Table 2 Ingredients and proximate composition of the experimental diets (\% DM)

\begin{tabular}{|c|c|c|c|c|}
\hline & \multicolumn{4}{|c|}{ Experimental diets } \\
\hline & $\mathrm{FO}$ & LO & SO & Lard \\
\hline \multicolumn{5}{|l|}{ Ingredients (\% DM) } \\
\hline Anchovy FM ${ }^{1}$ & 55.0 & 55.0 & 55.0 & 55.0 \\
\hline Casein & 5.0 & 5.0 & 5.0 & 5.0 \\
\hline Wheat gluten & 10.0 & 10.0 & 10.0 & 10.0 \\
\hline Wheat flour & 20.0 & 20.0 & 20.0 & 20.0 \\
\hline Fish oil & 6.0 & - & - & - \\
\hline Linseed oil & - & 6.0 & - & - \\
\hline Soybean oil & - & - & 6.0 & - \\
\hline Lard & - & - & - & 6.0 \\
\hline Vitamin premix ${ }^{2}$ & 1.5 & 1.5 & 1.5 & 1.5 \\
\hline Mineral premix ${ }^{3}$ & 1.8 & 1.8 & 1.8 & 1.8 \\
\hline Stay-C (50\%) & 0.3 & 0.3 & 0.3 & 0.3 \\
\hline Vitamin E (25\%) & 0.2 & 0.2 & 0.2 & 0.2 \\
\hline Choline (50\%) & 0.2 & 0.2 & 0.2 & 0.2 \\
\hline \multicolumn{5}{|c|}{$\begin{array}{l}\text { Proximate composition } \\
(\% \text { DM) }\end{array}$} \\
\hline Dry matter & 70.5 & 63.7 & 66.8 & 60.4 \\
\hline Crude protein & 56.0 & 56.2 & 56.8 & 56.9 \\
\hline Crude lipid & 13.0 & 13.2 & 13.2 & 13.3 \\
\hline Ash & 11.0 & 11.0 & 11.0 & 11.2 \\
\hline \multicolumn{5}{|l|}{$\begin{array}{l}\text { Fatty acids } \\
\text { (\% total fatty acids) }\end{array}$} \\
\hline $14: 0$ & 8.5 & 1.7 & 1.6 & 3.0 \\
\hline 16:0 & 21.2 & 11.2 & 15.1 & 22.7 \\
\hline 18:0 & 4.5 & 4.2 & 4.5 & 10.1 \\
\hline $16: 1 n-7$ & 8.3 & 0.9 & 0.8 & 2.2 \\
\hline $18: 1 n-9(O A)^{4}$ & 8.3 & 14.3 & 20.7 & 32.8 \\
\hline $18: 2 n-6(L A)^{5}$ & 1.6 & 11.2 & 32.7 & 8.1 \\
\hline $18: 3 n-3(A L A)^{6}$ & 0.7 & 33.7 & 4.2 & 0.4 \\
\hline $20: 4 n-6$ & 0.8 & 0.7 & 0.7 & 0.7 \\
\hline $20: 5 n-3(E P A)^{7}$ & 14.5 & 3.7 & 3.6 & 3.6 \\
\hline $22: 5 n-3$ & 11.4 & 0.6 & 0.6 & 0.6 \\
\hline $22: 6 n-3(D H A)^{8}$ & 16.6 & 12.4 & 12.1 & 12.3 \\
\hline
\end{tabular}

FO fish oil, $L O$ linseed oil, $S O$ soybean oil

${ }^{1}$ Pesquera Bahia Caldera, Caldera, Chile; with crude protein $69.1 \%$, crude lipid $12.6 \%$, ash $14.1 \%$ dry matter

${ }^{2}$ Vitamin premix contained the following amounts which were diluted in cellulose ( $\mathrm{g} / \mathrm{kg}$ premix): DL-a-tocopheryl acetate, 18.8 ; thiamin

hydrochloride, 2.7; riboflavin, 9.1; pyridoxine hydrochloride, 1.8; niacin

36.4; Ca-D-pantothenate, 12.7; myo-inositol, 181.8; D-biotin, 0.27; folic

acid, 0.68; $\mathrm{p}$-aminobenzoic acid, 18.2; menadione, 1.8; retinyl acetate,

0.73; cholecalciferol, 0.003; cyanocobalamin, 0.003

${ }^{3}$ Mineral premix contained the following ingredients ( $\mathrm{g} / \mathrm{kg}$ premix):

$\mathrm{MgSO}_{4} \cdot 7 \mathrm{H}_{2} \mathrm{O}, 80.0 ; \mathrm{NaH}_{2} \mathrm{PO}_{4} \cdot 2 \mathrm{H}_{2} \mathrm{O}, 370.0 ; \mathrm{KCl}, 130.0$; ferric citrate, 40.0;

$\mathrm{ZnSO}_{4} \cdot 7 \mathrm{H}_{2} \mathrm{O}, 20.0 ; \mathrm{Ca}$-lactate, 356.5; $\mathrm{CuCl}, 0.2 ; \mathrm{AlCl}_{3} \cdot 6 \mathrm{H}_{2} \mathrm{O}, 0.15 ; \mathrm{Kl}, 0.15$

$\mathrm{Na}_{2} \mathrm{Se}_{2} \mathrm{O}_{3}, 0.01 ; \mathrm{MnSO}_{4} \cdot \mathrm{H}_{2} \mathrm{O}, 2.0 ; \mathrm{CoCl}_{2} \cdot 6 \mathrm{H}_{2} \mathrm{O}, 1.0$

${ }^{4}$ Oleic acid

${ }^{5}$ Linoleic acid

${ }^{6} \mathrm{a}$-Linolenic acid

${ }^{7}$ Eicosapentaenoic acid

${ }^{8}$ Decosahexaenoic acid
Fish and experimental design

Mandarin fish juveniles were obtained from Inland Fisheries Research Institute (Chungcheongbuk-do, South Korea). The fish were acclimated to the experimental condition in a 5000-L glass tank, connected to a recirculation system, at the GWNU Marine Biology Center in ambient freshwater temperature $\left(24 \pm 0.1^{\circ} \mathrm{C}\right.$, mean $\left.\pm \mathrm{SE}\right)$, feeding on a repelleted commercial feed (50\% crude protein and 13\% lipid; Woosung, Daejeon, South Korea) with the same size as the experimental diets. Following the 1-week acclimation procedure, 25 fish with an initial mean body weight of $1.8 \pm 0.03 \mathrm{~g}$ were randomly stocked into each 65-L polyvinyl circular tank supplied with filtered and dechlorinated tap water using a freshwater recirculating (closed) system. Triplicate groups of fish were fed one of the formulated diets to apparent satiation twice a day at 09:00 and 17:00 for 12 weeks. The uneaten feed was siphoned out, dried to constant weight, and then weighed to estimate the amount of feed consumed. The mean water temperature during the experimental period was $24 \pm 0.1^{\circ} \mathrm{C}$. The photoperiod was maintained on a 12:12-h (light/dark) schedule. Fish were deprived of feed for $16 \mathrm{~h}$ prior to weighing or sampling to minimize handling stress on fish.

\section{Sample collection}

At the end of the experiment, all the survived fish in each tank were counted and weighed for calculation of growth performance, feed utilization parameters, and survival rates. Total body length was measured for each individual fish to the nearest $0.1 \mathrm{~mm}$. A random sample of 5 fish per tank was collected and stored at $-43^{\circ} \mathrm{C}$ for subsequent whole body proximate composition analyses.

Blood samples were collected from the caudal veins of six anesthetized $(200 \mathrm{mg} / \mathrm{L}$ MS-222, Sigma, St. Louis, MO, USA) individual fish per tank (nine fish/dietary treatment) using heparinized syringes. Blood samples were kept on ice prior to plasma separation by centrifugation at $7500 \mathrm{RPM}$ for $10 \mathrm{~min}$ using a high-speed refrigerated microcentrifuge (HanilBioMed Inc., Gwangju, South Korea). Plasma samples were immediately stored at $-80^{\circ} \mathrm{C}$ until used in subsequent hematological analyses including total protein (TP), total cholesterol (TCHO), aspartate aminotransferase (AST), alanine aminotransferase (ALT), alkaline phosphatase (ALP), albumin (ALB), and total bilirubin (TBIL). Immediately after blood sampling, fish (6 fish/tank; 18 fish/dietary treatment) were dissected to obtain their liver and visceral weights for calculating the hepatosomatic (HSI) and viscerosomatic (VSI) indices, respectively. Fillet samples were subsequently dissected out of the same fish and stored at $-80^{\circ} \mathrm{C}$ until proximate and fatty acid composition analyses. 


\section{Analytical methods \\ Chemical composition analyses}

Chemical composition of the experimental diets, whole body, and fillet samples was determined according to the standard methods (AOAC 2005). Moisture content was estimated by oven drying at $105^{\circ} \mathrm{C}$ for $6 \mathrm{~h}$. Crude protein content was determined by an automated Kjeldahl system (Buchi, Flawil, Switzerland). Crude lipid was measured using a Soxhlet extractor (VELP Scientifica, Milano, Italy), and ash content by a Thermolyne ${ }^{\mathrm{Tm}}$ combustion in a muffle furnace at $600{ }^{\circ} \mathrm{C}$ for $4 \mathrm{~h}$.

\section{Hematological analysis}

Plasma samples were analyzed for TP, TCHO, AST, ALT, ALP, ALB, and TBIL concentrations using an automated blood analyzer (DRI-CHEM NX500i, FUJIFILM Corporation Tokyo, Japan).

\section{Fatty acid analyses}

Total lipids in oil sources, experimental diets, and fillet samples were extracted following the Folch et al. (1957) method using a chloroform and methanol mixture $(2: 1 \mathrm{v} / \mathrm{v})$. Extracted lipids were then submitted to acid-catalyzed transmethylation using $\mathrm{BF}_{3}-\mathrm{MeOH}$ (Sigma, St. Louis, $\mathrm{MO}$, USA) to obtain fatty acid methyl esters (FAMEs). Then, FAMEs were analyzed using a PerkinElmer Clarus 600 gas chromatograph (Shelton, CT, USA) equipped with a flame-ionization detector and a SP-2560 capillary column $(100 \mathrm{~m} \times 0.25 \mathrm{~mm}$ i.d., 0.2- $\mu \mathrm{m}$ film thickness; Supelco, Bellefonte, PA, USA) using helium as the carrier gas and temperature programmed operation from 140 to $240{ }^{\circ} \mathrm{C}$ in increments of $5^{\circ} \mathrm{C} / \mathrm{min}$. The temperature of both injector and detector was adjusted at $240^{\circ} \mathrm{C}$. Fatty acids were identified by comparison with standard FAME mixtures (FAME 37 and PUFA 3; Supelco, Bellefonte, PA, USA) and data analyzed using TotalChrom software (version 6.3.1; PerkinElmer Inc., Shelton, CT, USA).

\section{Formulae, calculations, and statistical analysis}

Weight gain (WG, \%) =

[(final body weight-initial body weight $) /$ initial body weight $] \times 100$

Specific growth rate $(\mathrm{SGR}, \% /$ day $)=$

[( $\ln$ final body weight- $\ln$ initial body weight $) /$ days $] \times 100$

Daily feed intake (DFI, \%) =

\{total dry feed consumed $(\mathrm{g}) /[$ (initial fish weight + final fish weight + dead fish weight $) \times$ days $/ 2]\} \times 100$

Daily protein intake (DPI, \%) =

\{total protein consumed $(\mathrm{g}) /[$ (initial fish weight

+ final fish weight + dead fish weight $) \times$ days $/ 2]\} \times 100$

Feed efficiency $(\mathrm{FE}, \%)=$

(wet weight gain $(\mathrm{g}) /$ total dry feed consumed $(\mathrm{g})) \times 100$
Protein efficiency ratio $(\mathrm{PER})=$ wet weight gain $(\mathrm{g}) /$ total protein consumed $(\mathrm{g})$

Condition factor $(\mathrm{CF}, \%)=$

$\left[\right.$ fish body weight $/($ total length of fish $\left.)(\mathrm{cm})^{3}\right] \times 100$

Hepatosomatic index (HSI, \%) = (liver weight $(\mathrm{g}) /$ fish body weight $) \times 100$

Viscerosomatic index (VSI, \%) =

(viscera weight $(\mathrm{g}) /$ fish body weight $) \times 100$

Data were analyzed as a completely random design with the tank as the experimental unit, using one-way ANOVA in SPSS program version 22.0 (SPSS Inc., Chicago, IL, USA). When ANOVA identified differences among groups, Tukey's honest significant difference multiple range test was performed to detect statistically significant differences between mean responses at a significance level of $P<0.05$. Data were checked for normal distribution (Shapiro-Wilk's test) and homogeneity of variances (Levene's test) and when necessary arcsine transformed. Data were presented as mean \pm standard error (SE.) of the triplicate groups.

\section{Results}

The results of growth, feed utilization, and morphological parameters of mandarin fish juveniles are presented in Table 3. The total replacement of dietary FO by different lipid sources showed no significant negative effect on growth performance in terms of final body weight (10.311.6 g), WG (499-549\%), and SGR (2.13-2.23\%). Although growth rates were not significantly affected, fish received FO and LO diets grew slightly better and were numerically larger than those fed the other two diets. The DFI of fish fed the SO diet was significantly higher than those of fish fed FO and LO diets. No remarkable differences on DPI, FE, and PER were observed among any of the treatments $(P>0.05)$. The survival rate was higher than $97 \%$, and there was no significant difference among all experimental groups. Similarly, the total substitution of FO with LO, SO, or lard had no significant effects on fish morphological parameters.

The results of whole body proximate composition are presented in Table 4. No significant differences were observed in whole body composition in terms of moisture, crude protein, and ash contents among all experimental groups. Total replacement of dietary FO with three different oil sources resulted in increased fat levels in mandarin fish body. Fish fed the LO and SO diets had significantly higher crude lipid level in the whole body than that of fish fed FO diet.

The results of hematological parameters are reported in Table 5. There was neither a considerable difference 
Table 3 Growth performance, feed utilization efficiency, and morphological parameters of mandarin fish fed the four experimental diets for 12 weeks

\begin{tabular}{lllll}
\hline \multicolumn{5}{l}{ Experimental diets } \\
\cline { 2 - 5 } & FO & LO & SO & Lard \\
\hline $\mathrm{IBW}^{1}$ & $1.8 \pm 0.02$ & $1.8 \pm 0.02$ & $1.7 \pm 0.01$ & $1.8 \pm 0.02$ \\
$\mathrm{FBW}^{2}$ & $11.6 \pm 0.3$ & $10.9 \pm 0.3$ & $10.3 \pm 0.03$ & $10.7 \pm 0.4$ \\
$\mathrm{WG}^{3}$ & $549 \pm 20$ & $524 \pm 18$ & $503 \pm 1$ & $499 \pm 13$ \\
$\mathrm{SGR}^{4}$ & $2.23 \pm 0.04$ & $2.18 \pm 0.04$ & $2.14 \pm 0.00$ & $2.13 \pm 0.03$ \\
$\mathrm{DFI}^{5}$ & $2.54 \pm 0.10^{\mathrm{a}}$ & $2.50 \pm 0.06^{\mathrm{a}}$ & $2.81 \pm 0.02^{\mathrm{b}}$ & $2.72 \pm 0.04^{\mathrm{ab}}$ \\
$\mathrm{DPI}^{6}$ & $1.44 \pm 0.06$ & $1.42 \pm 0.03$ & $1.57 \pm 0.01$ & $1.53 \pm 0.02$ \\
$\mathrm{FE}^{7}$ & $69.1 \pm 3.2$ & $69.1 \pm 2.3$ & $61.4 \pm 0.8$ & $62.5 \pm 1.2$ \\
$\mathrm{PER}^{8}$ & $1.44 \pm 0.06$ & $1.45 \pm 0.04$ & $1.31 \pm 0.01$ & $1.34 \pm 0.02$ \\
$\mathrm{Survival}^{8}$ & $98.7 \pm 1.33$ & $97.3 \pm 1.33$ & $98.7 \pm 1.33$ & $98.7 \pm 1.33$ \\
$\mathrm{CF}^{9}$ & $1.14 \pm 0.11$ & $1.41 \pm 0.06$ & $1.17 \pm 0.02$ & $1.14 \pm 0.11$ \\
$\mathrm{HSI}^{10}$ & $2.06 \pm 0.10$ & $3.04 \pm 0.57$ & $2.47 \pm 0.28$ & $2.24 \pm 0.09$ \\
VSI $^{11}$ & $9.93 \pm 0.73$ & $10.42 \pm 0.50$ & $9.65 \pm 0.74$ & $8.95 \pm 0.30$
\end{tabular}

Values are mean of triplicate groups and presented as mean \pm SE. Values with different superscripts in the same row are significantly different $(P<0.05)$. The lack of superscript letter indicates no significant differences among treatments FO fish oil, $L O$ linseed oil, SO soybean oil

${ }^{1}$ Initial mean body weight $(\mathrm{g})$

${ }^{2}$ Final mean body weight $(\mathrm{g})$

${ }^{3}$ Weight gain $(\%)=[($ final bodyweight - initial bodyweight $) /$ initial body weight $] \times 100$

${ }^{4}$ Specific growth rate $(\% /$ day $)=[($ In final

bodyweight - In initial bodyweight]/days $] \times 100$

${ }^{5}$ Daily feed intake $(\%)=$ total dry feed consumed $(\mathrm{g}) /[($ initial fish weight + final fishweight + dead fishweight $) \times$ days $/ 2]\} \times 100^{6}$ Daily protein intake $(\%)=$ total protein consumed $(\mathrm{g}) /[$ (initial fishweight + final

fishweight + dead fishweight $) \times$ days $/ 2]\} \times 100$

${ }^{7}$ Feed efficiency $(\%)=($ wet weight gain $(\mathrm{g}) /$ total dry feed consumed $(\mathrm{g})) \times 100$

${ }^{8}$ Protein efficiency ratio $=$ wet weight gain $(\mathrm{g}) /$ total protein consumed $(\mathrm{g})$

${ }^{9}$ Condition factor $(\%)=\left[\right.$ fish body weight $/\left(\right.$ total length of fish) $\left.(\mathrm{cm})^{3}\right] \times 100$

${ }^{10}$ Hepatosomatic index $(\%)=($ liver weight $(\mathrm{g}) /$ fish body weight $) \times 100$

${ }^{11}$ Viscerosomatic index $(\%)=($ viscera weight $(\mathrm{g}) /$ fish body weight $) \times 100$

nor any discernible trend among dietary groups regarding plasma hematological parameters.

Results on fillet proximate composition and fatty acid profile are given in Table 6 . No significant effect nor any defined trend was found in fillet proximate composition among dietary treatments. However, the addition of vegetable oil or animal fat in fish diet significantly

Table 4 Whole body proximate composition of mandarin fish fed the four experimental diets for 12 weeks (\% wet weight)

\begin{tabular}{lllll}
\hline \multirow{5}{*}{} & \multicolumn{4}{l}{ Experimental diets } \\
\cline { 2 - 5 } & FO & LO & SO & Lard \\
\hline Moisture & $79.1 \pm 1.5$ & $77.0 \pm 0.6$ & $76.7 \pm 1.7$ & $77.8 \pm 1.52$ \\
Crude protein & $11.3 \pm 0.6$ & $11.8 \pm 0.5$ & $13.4 \pm 0.9$ & $12.4 \pm 1.8$ \\
Crude lipid & $3.85 \pm 0.17^{\mathrm{a}}$ & $5.95 \pm 0.34^{\mathrm{b}}$ & $5.80 \pm 0.12^{\mathrm{b}}$ & $4.84 \pm 0.67^{\mathrm{ab}}$ \\
Ash & $3.34 \pm 0.12$ & $3.36 \pm 0.21$ & $3.55 \pm 0.48$ & $3.51 \pm 0.24$
\end{tabular}

Values are mean of triplicate groups and presented as mean \pm SE. Values with different superscripts in the same row are significantly different $(P<0.05)$. The lack of superscript letter indicates no significant differences among treatments FO fish oil, $L O$ linseed oil, SO soybean oil
Table 5 Hematological parameters of mandarin fish fed the four experimental diets for 12 weeks

\begin{tabular}{lllll}
\hline \multicolumn{5}{l}{ Experimental diets } \\
\cline { 2 - 5 } & FO & LO & SO & Lard \\
\hline $\mathrm{TP}^{1}$ & $4.33 \pm 0.17$ & $4.17 \pm 0.20$ & $4.03 \pm 0.32$ & $4.80 \pm 0.12$ \\
$\mathrm{TCHO}^{2}$ & $205 \pm 8$ & $190 \pm 13$ & $187 \pm 13$ & $219 \pm 9$ \\
$\mathrm{AST}^{3}$ & $174 \pm 16$ & $224 \pm 61$ & $172 \pm 22$ & $274 \pm 11$ \\
$\mathrm{ALT}^{4}$ & $10.0 \pm 0.6$ & $10.0 \pm 0.0$ & $8.7 \pm 0.3$ & $11.0 \pm 6.7$ \\
$\mathrm{ALP}^{5}$ & $412 \pm 30$ & $342 \pm 30$ & $341 \pm 40$ & $489 \pm 34$ \\
$\mathrm{ALB}^{6}$ & $0.77 \pm 0.03$ & $0.67 \pm 0.03$ & $0.70 \pm 0.06$ & $0.83 \pm 0.03$ \\
$\mathrm{TBIL}^{7}$ & $0.53 \pm 0.09$ & $0.60 \pm 0.12$ & $0.77 \pm 0.09$ & $0.73 \pm 0.17$
\end{tabular}

Values are mean of triplicate groups and presented as mean \pm SE. Values with different superscripts in the same row are significantly different $(P<0.05)$. The lack of superscript letter indicates no significant differences among treatments FO fish oil, $L O$ linseed oil, SO soybean oil

${ }^{1}$ Total protein $(\mathrm{g} / \mathrm{dL})$

${ }^{2}$ Total cholesterol (mg/dL)

${ }^{3}$ Asparatet aminotransferase activity (U/L)

${ }^{4}$ Alanine aminotransferase activity $(\mathrm{U} / \mathrm{L})$

${ }^{5}$ Alkaline phosphatase (U/L)

${ }^{6}$ Albumin $(\mathrm{g} / \mathrm{dL})$

${ }^{7}$ Total bilirubin $(\mathrm{mg} / \mathrm{dL})$

altered fillet fatty acid profile. Regarding saturated fatty acids (SFAs), the highest content of myristic acid (14:0) was noted in fish fed the FO diet, which differed significantly from the other three dietary treatments. Fillets of fish fed diets containing lard in place of FO had significantly higher levels of palmitic acid (16:0) than do fillets of fish fed the other experimental diets. While no statistically significant differences were found among LO, SO, and lard groups, the stearic acid (18:0) content of fillet in lard group was significantly higher than that of FO-fed fish. With respect to monounsaturated fatty acids (MUFAs), fillets of fish fed FO and lard diets contained significantly higher palmitoleic acid (16:1n-7) compared to fish fed on LO and SO diets. A significantly greater level of OA was found in the fillet of fish fed lard diet compared to the other dietary groups. By evaluation of n-6 fatty acid levels in the fish fillet, the highest concentration of LA was found in fish fed on diets containing SO. Alternative oil treatments had no significant impact on fillet arachidonic acid (AA, 20:4n-6) content. With respect to the fillet $\mathrm{n}-3$ fatty acid composition, fish fed the LO diet had significantly higher levels of ALA than that of fish fed the FO-based diet, which was itself significantly higher than those found in the SO and lard groups. Fillets of fish fed diets containing FO had significantly higher concentrations of EPA than those fed diets containing the other three oil sources. The 22:5n-3 content of fillet in FO fish was significantly higher than that of lard diet-fed fish, while no significant differences in fillet 22:5n-3 among LO, SO, and lard diet-fed fish were observed. The DHA contents of the fish fillets were numerically lower in the $\mathrm{LO}, \mathrm{SO}$, and lard groups compared to fish fed the FO diet. 
Table 6 Fillet proximate and fatty acid composition of mandarin fish fed the four experimental diets for 12 weeks

\begin{tabular}{|c|c|c|c|c|}
\hline & \multicolumn{4}{|c|}{ Experimental diets } \\
\hline & $\mathrm{FO}$ & $\mathrm{LO}$ & $\mathrm{SO}$ & Lard \\
\hline \multicolumn{5}{|c|}{$\begin{array}{l}\text { Proximate composition } \\
\text { (\% wet weight) }\end{array}$} \\
\hline Moisture & $77.9 \pm 0.8$ & $79.1 \pm 0.4$ & $78.7 \pm 1.2$ & $77.6 \pm 0.4$ \\
\hline Crude protein & $18.1 \pm 0.5$ & $18.1 \pm 0.8$ & $17.6 \pm 0.9$ & $18.8 \pm 0.6$ \\
\hline Crude lipid & $1.44 \pm 0.36$ & $1.70 \pm 0.27$ & $1.36 \pm 0.17$ & $1.32 \pm 0.24$ \\
\hline Ash & $1.37 \pm 0.16$ & $1.03 \pm 0.11$ & $1.14 \pm 0.09$ & $1.46 \pm 0.02$ \\
\hline \multicolumn{5}{|c|}{ Fatty acid (\% total fatty acid) } \\
\hline 14:0 & $2.54 \pm 0.17^{b}$ & $1.84 \pm 0.12^{\mathrm{a}}$ & $1.45 \pm 0.02^{\mathrm{a}}$ & $1.68 \pm 0.03^{\mathrm{a}}$ \\
\hline $16: 0$ & $21.8 \pm 0.5^{\mathrm{a}}$ & $20.8 \pm 0.1^{\mathrm{a}}$ & $20.8 \pm 0.2^{\mathrm{a}}$ & $23.4 \pm 0.7^{b}$ \\
\hline $18: 0$ & $5.30 \pm 0.12^{\mathrm{a}}$ & $5.91 \pm 0.14^{\mathrm{ab}}$ & $6.01 \pm 0.28^{\mathrm{ab}}$ & $6.64 \pm 0.25^{b}$ \\
\hline $16: 1 n-7$ & $5.61 \pm 0.58^{b}$ & $2.42 \pm 0.18^{\mathrm{a}}$ & $2.49 \pm 0.37^{\mathrm{a}}$ & $4.94 \pm 0.12^{b}$ \\
\hline $18: 1 n-9(\mathrm{OA})^{1}$ & $21.5 \pm 1.7^{\mathrm{a}}$ & $21.2 \pm 0.7^{\mathrm{a}}$ & $20.3 \pm 0.1^{\mathrm{a}}$ & $27.98 \pm 1.2^{b}$ \\
\hline $18: 2 n-6(L A)^{2}$ & $4.90 \pm 0.31^{\mathrm{a}}$ & $7.38 \pm 0.20^{b}$ & $15.86 \pm 0.45^{c}$ & $6.29 \pm 0.39^{\mathrm{ab}}$ \\
\hline $18: 3 n-3(A L A)^{3}$ & $4.90 \pm 0.28^{b}$ & $10.47 \pm 0.48^{c}$ & $2.78 \pm 0.31^{\mathrm{a}}$ & $1.67 \pm 0.02^{\mathrm{a}}$ \\
\hline $20: 4 n-6$ & $1.92 \pm 0.32$ & $1.09 \pm 0.04$ & $1.09 \pm 0.02$ & $1.42 \pm 0.04$ \\
\hline $20: 5 n-3(E P A)^{4}$ & $6.20 \pm 0.31^{b}$ & $4.96 \pm 0.05^{\mathrm{a}}$ & $4.49 \pm 0.13^{\mathrm{a}}$ & $4.59 \pm 0.38^{a}$ \\
\hline $22: 5 n-3$ & $1.56 \pm 0.15^{b}$ & $1.42 \pm 0.05^{\mathrm{ab}}$ & $1.30 \pm 0.03^{\mathrm{ab}}$ & $1.04 \pm 0.13^{\mathrm{a}}$ \\
\hline $22: 6 n-3(\mathrm{DHA})^{5}$ & $18.2 \pm 1.8$ & $16.4 \pm 1.0$ & $15.7 \pm 0.2$ & $14.0 \pm 1.9$ \\
\hline
\end{tabular}

Values are mean of triplicate groups and presented as mean \pm SE. Values with different superscripts in the same row are significantly different $(P<0.05)$. The lack of superscript letter indicates no significant differences among treatments

FO fish oil, $L O$ linseed oil, SO soybean oil

${ }^{1}$ Oleic acid

${ }^{2}$ Linoleic acid

${ }^{3} a$-Linolenic acid

${ }^{4}$ Eicosapentaenoic acid

${ }^{5}$ Decosahexaenoic acid

\section{Discussion}

The growth rate values observed in the present study were much higher than those previously reported for the same species by our research team using practical diets with relatively similar protein and lipid contents (Sankian et al. 2017, 2018). This is probably due to the higher initial weight of the fish in the previous studies ( $8-20$ vs. $1.8 \mathrm{~g}$ in the present study). To our knowledge, so far, there is no previous record on the effects of different dietary lipid source on growth, feed utilization, hematological indices, and body/fillet nutritional traits of mandarin fish. The findings of the present study showed that FO in a practical diet with $13 \%$ lipid for juvenile mandarin fish can be completely replaced by $\mathrm{LO}, \mathrm{SO}$, or lard without markedly compromising growth performance and feed efficiency. Our results are in agreement with the previous studies in which it was demonstrated that various alternative oils could be used to completely replace FO in freshwater fish diets without any adverse effect on the nutrient utilization or growth rates (Turchini et al. 2011a; Kowalska et al. 2012; Jiang et al. 2013; Han et al. 2013; Zhou et al. 2016). However, the DFI value in fish fed with SO diet was significantly higher than those of fish fed the FO and LO diets. Similarly, Du et al. (2008) found markedly higher feed intake in grass carp, Ctenopharyngodon idella, fngerlings fed lard or a blend of vegetable oils in comparison with a FO-based diet. A large body of literature provides strong evidence to suggest that fish are able to regulate feed intake in order to meet their metabolizable energy demands (De la Higuera 2001). Within the context of FO replacement in aquafeed, if $\mathrm{FO}$ is replaced with an equal amount of alternative oil source, minimal differences in the total dietary energy content are expected. However, since different oils may have different digestibility, it is possible that the total digestible/metabolizable energy of feed can be partially changed, resulting in variations in feed intake. This may partly explain the DFI differences observed in the present study.

The replacement of the dietary FO by three different oils, in the present study, did not affect the morphological indices of fish, which is often used to indicate the nutritional status of fish. This was in agreement with previous studies in other freshwater species, which reported that the replacement of dietary FO with vegetable oils and rendered animal fat did not affect the morphological parameters of snakehead, Murray cod, rainbow 
trout, darkbarbel catfish, Nile tilapia, and gibel carp (Figueiredo-Silva et al. 2005; Turchini et al. 2011a; Aliyu-Paiko and Hashim 2012; Jiang et al. 2013; Peng et al. 2015; Zhou et al. 2016).

In the present study, the whole body lipid content of mandarin fish fed the LO and SO diets were significantly higher than that of fish fed the FO diet. In accordance with the present study, significantly high fat was recorded by Aliyu-Paiko and Hashim (2012) in whole body proximate composition of snakehead fingerlings, fed palm oil as a FO replacer. Similarly, in hybrid tilapia, Oreochromis niloticus $\times$ O. aureus, fed tea see oil for 10 weeks, significantly higher body lipid levels were obtained compared to fish fed FO (Han et al. 2013). It has been suggested that diets enriched in n-3 LC-PUFA may suppress fatty acids synthesis, simulate fatty acid $\beta$-oxidation, activate lipoprotein lipase, and reduce triacylglycerol synthesis, thereby leading to an overall reduction in lipid deposition and suppressing the development of obesity in mammals (Al-Hasani and Joost 2005; Madsen et al. 2005). Indeed, Todorčević et al. (2009) reported that feeding FO to Atlantic salmon, Salmo salar, for 21 weeks reduced white adipose tissue fat content and increased fatty acid $\beta$-oxidation activity compared to fish fed rapeseed oil.

Hematological parameters are important indicators of fish's physiological and health status (Maita 2007). Hematological responses of juvenile mandarin fish were unaffected by the complete substitution of FO in this study. There are conflicting reports concerning the effects of FO substitution by other oil sources on hematological indices, with some studies suggesting marked modifications (Ferreira et al. 2011; Peng et al. 2015; Mozanzadeh et al. 2016), while others show no discernible effects (Figueiredo-Silva et al. 2005; Twibell et al. 2012). This discrepancy can be attributed to various factors including fish species, life stage, composition and nutrient content of the diet, source or quality of the alternative oil source, and experimental conditions, mainly water temperature. However, since dietary FO replacement with alternative oils caused no detectable change either in morphological indices or in hematological parameters of juvenile mandarin fish in the present study, it can be concluded that fish were in overall good health and nutritional status.

The fatty acid composition of mandarin fish fillets closely resembled those of the experimental diets, with fish fed the LO, SO, and lard having remarkably elevated levels of ALA, LA, and OA, respectively. It is well documented that the fatty acid profile of farmed-fish fillets reflects the fatty acid composition of the dietary oil used (Bell et al. 1994). Although replacement of FO with alternative oils resulted in reduced levels of EPA and DHA, the levels of these fatty acids in the fish fillets were still higher than their respective levels in diets. This could be due either to selective retention and/or active synthesis of these fatty acids (Turchini et al. 2011b). Similar results were observed in other freshwater fish species such as rainbow trout (Caballero et al. 2002; Turchini and Francis 2009), Murray cod (Turchini et al. 2006), common carp (Ren et al. 2012), tilapia (Al-Souti et al. 2012, Li et al. 2016), Chinese long snout catfish, Leiocassis longirostris Günther (Choi and Lee 2015), and silver barb, Puntius gonionotus (Nayak et al. 2017). It is widely believed that freshwater fish can convert $C_{18}$ PUFA of both n- 6 and $n-3$ series to their corresponding LC-PUFA via a series of desaturation and elongation reactions (NRC 2011; Turchini et al. 2011b). However, the capacity of $\mathrm{C}_{18}$ PUFAs desaturation/elongation to $\mathrm{n}-3$ LC-PUFAs is depended on the species (Sargent et al. 2002). Therefore, the decreased deposition of dietary ALA, LA, and OA along with good growth, feed utilization, and survival in this study is suggestive of the ability of mandarin fish to meet their essential fatty acid requirement by the use of $\mathrm{C}_{18}$ PUFA. It could also be assumed that residual fish oil from dietary FM was probably adequate to provide essential fatty acids for normal growth and development of juvenile mandarin fish. The results of this experiment presented a higher retention of DHA in fish fed vegetable oil-based or lard diets. Previous studies in which fish were fed vegetable oil-based diets reported high DHA retention in the muscles of salmonids (Bell et al. 2001, 2003; Caballero et al. 2002; Thanuthong et al. 2011). The preferred retention of DHA over EPA may also indicate a selective utilization of EPA over DHA when dietary levels decrease, as a means of meeting the requirements for tissue membrane integrity and function (Fountoulaki et al. 2009).

\section{Conclusion}

This study indicates that total FO replacement with LO, $\mathrm{SO}$, or lard can be tolerated by juvenile mandarin fish without any pronounced adverse effects on fish performance and health. The abundance of $\mathrm{C}_{18}$ PUFAs provided by tested alternative oil sources coupled with some n-3 LC-PUFA from the residual lipid of FM in the basal diet appeared to meet the essential fatty acid requirements of $\sim 1.8 \mathrm{~g}$ mandarin fish under the conditions of the present study. This probably stemmed from the ability of this species to bioconvert $\mathrm{C}_{18}$ PUFA to their corresponding LC-PUFA and selectively retain EPA and DHA to some extent. Our findings therefore suggest that mandarin fish juveniles have high tolerance to diets that differ markedly in fatty acid composition.

\section{Abbreviations}

AA: Arachidonic acid; ALA: a-Linolenic acid; ALB: Albumin; ALP: Alkaline

phosphatase; ALT: Alanine aminotransferase; AST: Aspartate aminotransferase; 
CF: Condition factor; DFI: Daily feed intake; DHA: Docosahexaenoic acid; DPI: Daily protein intake; EPA: Eicosapentaenoic acid; FE: Feed efficiency; FM: Fish meal; FO: Fish oil; HIS: Hepatosomatic index; LA: Linoleic acid; LCPUFA: Long-chain polyunsaturated fatty acid; LO: Linseed oil; OA: Oleic acid; PER: Protein efficiency ratio; SGR: Specific growth rate; SO: Soybean oil; TCHO: Total cholesterol; TP: Total protein; VSI: Viscerosomatic index; WG: Weight gain

\section{Acknowledgements}

This research was financially supported by the Fishery Commercialization Technology Development Program [20150575] funded by the Korean Ministry of Oceans and Fisheries and Basic Science Research Program through the National Research Foundation of Korea (NRF) funded by the Ministry of Education (No. 2018R1A6A1A03023584).

\section{Funding}

This study was financially supported by the Fishery Commercialization Technology Development Program [20150575] funded by the Korean Ministry of Oceans and Fisheries and Basic Science Research Program through the National Research Foundation of Korea (NRF) funded by the Ministry of Education (No.2018R1A6A1A03023584). The funding organizations played an active role in the manufacturing of the experimental diets and analyses.

\section{Availability of data and materials}

All datasets generated and/or analyzed during the current study are available from the corresponding author on reasonable request.

\section{Authors' contributions}

ZS and SKH manufactured the experimental feed, performed the analyses, and drafted the manuscript. YOK conducted the feeding trial. SML conceived and designed the study and experimental facility and also revised the manuscript. All authors read and approved the final manuscript.

\section{Ethics approval and consent to participate}

Experimental protocols followed the guidelines approved by the Animal Care and Use Committee of GWNU (GWNU-2017-9).

\section{Consent for publication}

Not applicable.

\section{Competing interests}

The authors declare that they have no competing interests.

\section{Publisher's Note}

Springer Nature remains neutral with regard to jurisdictional claims in published maps and institutional affiliations.

\section{Author details}

'Department of Marine Bioscience and Technology, Gangneung-Wonju National University, Gangneung 25457, South Korea. ${ }^{2}$ Department of Inland Fisheries Research Institute, Chungju 27329, South Korea.

\section{Received: 10 January 2019 Accepted: 11 April 2019}

\section{Published online: 25 April 2019}

\section{References}

Al-Hasani H, Joost HG. Nutrition-/diet-induced changes in gene expression in white adipose tissue. Best Pract Res Clin Endocrinol Metab. 2005;19:589-603.

Aliyu-Paiko M, Hashim R. Effects of substituting dietary fish oil with crude palm oil and palm fatty acid distillate on growth, muscle fatty acid composition and the activities of hepatic lipogenic enzymes in snakehead (Channa striatus, Bloch 1793) fingerling. Aquac Res. 2012;43:767-76.

Al-Souti A, Al-Sabahi J, Soussi B, Goddard S. The effects of fish oil-enriched diets on growth, feed conversion and fatty acid content of red hybrid tilapia, Oreochromis sp. Food Chem. 2012;133:723-7.

Apraku A, Liu L, Leng X, Rupia EJ, Ayisi CL. Evaluation of blended virgin coconut oil and fish oil on growth performance and resistance to Streptococcus iniae challenge of Nile tilapia (Oreochromis niloticus). EJBAS. 2017;4:175-84.

Association of Official Analytical Chemists (AOAC). Official methods of analysis. 18th ed. Gaithersburg: Association of Official Analytical Chemists; 2005.
Bell JG, McEvoy J, Tocher DR, McGhee F, Campbell PJ, Sargent JR. Replacement of fish oil with rapeseed oil in diets of Atlantic salmon (Salmo salar) affects tissue lipid composition and hepatocyte fatty acid metabolism. J Nutr. 2001;131:1535-43.

Bell JG, McGhee F, Campbell PJ, Sargent JR. Rapeseed oil as an alternative to marine fish oil in diets of post-smolt Atlantic salmon (Salmo salar): changes in flesh fatty acid composition and effectiveness of subsequent fish oil "wash out". Aquaculture. 2003;218:515-28.

Bell JG, Tocher DR, MacDonald FM, Sargent JR. Effects of diets rich in linoleic (18: $2 n-6)$ and a-linonenic (18:3n-3) acids on growth, lipid class and fatty acid compositions and eicosanoid production in juvenile turbot (Scophtalmus maximus L.). Fish Physiol Biochem. 1994;13:105-18.

Bureau DP, Meeker DL. Terrestrial animal fats. In: Turchini GM, Ng WK, Tocher DR, editors. Fish oil replacement and alternative lipid sources in aquaculture feeds. Boca Raton: CRC Press; 2011. p. 245-66.

Caballero MJ, Obach A, Rosenlund G, Montero D, Gisvold M, Izquierdo MS. Impact of different dietary lipid sources on growth, lipid digestibility, tissue fat composition and histology of rainbow trout, Oncorhynchus mykiss. Aquaculture. 2002;214:253-71.

Choi J, Lee SM. Effect of dietary lipid sources on body fatty acid composition of Chinese long snout catfish Leiocassis longirostris Günther. Fish Aquat Sci. 2015;18:359-65.

Chu W, Li W, Wang K, Liu L, Leng X, Zhang J. Comparative studies on muscle cellularity and flesh quality of two mandarin fish species, Siniperca chuatsi and Siniperca scherzeri. J Food Agric Environ. 2013;11:1600-5.

De la Higuera M. Effects of nutritional factors and feed characteristics on feed intake. In: Houlihan D, Boujard T, Jobling M, editors. Food intake in fish. Oxford: Blackwell Science Ltd.; 2001. p. 250-68.

Du ZY, Clouet P, Huang LM, Degrace P, Zheng WH, He JG, Tian LX, Liu YJ. Utilization of different dietary lipid sources at high level in herbivorous grass carp (Ctenopharyngodon idella): mechanism related to hepatic fatty acid oxidation. Aquac Nutr. 2008;14:77-92.

Ferreira MW, de Araujo FG, Costa DV, Rosa PV, Figueiredo HCP, Murgas LDS. Influence of dietary oil sources on muscle composition and plasma lipoprotein concentrations in Nile tilapia, Oreochromis niloticus. J World Aquacult Soc. 2011;42:24-33.

Figueiredo-Silva A, Rocha E, Dias J, Silva P, Rema P, Gomes E, Valente LMP. Partial replacement of fish oil by soybean oil on lipid distribution and liver histology in European sea bass (Dicentrarchus labrax) and rainbow trout (Oncorhynchus mykiss) juveniles. Aquac Nutr. 2005;11:147-55.

Folch J, Lees M, Sloane Stanley GH. A simple method for the isolation and purification of total lipids from animal tissues. J Biol Chem. 1957;226:497-509.

Fountoulaki E, Vasilaki A, Hurtado R, Grigorakis K, Karacostas I, Nengas I, Rigos G, Kotzamanis $Y$, Venou B, Alexis MN. Fish oil substitution by vegetable oils in commercial diets for gilthead sea bream (Sparus aurata L.); effects on growth performance, flesh quality and fillet fatty acid profile: recovery of fatty acid profiles by a fish oil finishing diet under fluctuating water temperatures. Aquaculture. 2009;289:317-26.

Gause BR, Trushenski J. Sparing fish oil with beef tallow in feeds for rainbow trout: effects of inclusion rates and finishing on production performance and tissue fatty acid composition. N Am J Aquacult. 2013;75:495-511.

Han CY, Zheng QM, Feng LN. Effects of total replacement of dietary fish oil on growth performance and fatty acid compositions of hybrid tilapia (Orechromis niloticus × O. aureus). Aquacult Int. 2013;21:1209-17.

Jiang X, Chen L, Qin J, Qin C, Jiang H, Li E. Effects of dietary soybean oil inclusion to replace fish oil on growth, muscle fatty acid composition, and immune responses of juvenile darkbarbel catfish, Pelteobagrus vachelli. Afr J Agric Res. 2013;8:1492-9.

Kowalska A, Zakes Z, Krzysztof Siwicki A, Jankowska B, Jarmołowicz S, DemskaZakes K. Impact of diets with different proportions of linseed and sunflower oils on the growth, liver histology, immunological and chemical blood parameters, and proximate composition of pikeperch Sander lucioperca (L.). Fish Physiol Biochem. 2012;38:375-88.

Lazzari R, Emanuelli T, Maschio D, Ferreira CC, Battisti EK, Radünz-Neto J. The inclusion of soybean oil in the diets of silver catfish (Rhamdia quelen) in relation to growth quality and fillet acceptability. Lat Am J Aquat Res. 2016;44:39-45.

Lee WO, Baek JM, Lee JH, Kim KH, Kim CH, Yoon SW. Sexual maturation and feeding habit of Korean mandarin fish, Siniperca scherzeri (Perciformes, Centropomidae) in the Seomjin river and Imjin river, Korea. Korean J Environ Ecol. 2012;26:57-66.

Li FJ, Lin X, Lin SM, Chen WY, Guan Y. Effects of dietary fish oil substitution with linseed oil on growth, muscle fatty acid and metabolism of tilapia (Oreochromis niloticus). Aquac Nutr. 2016;22:499-508. 
Li S. Geographical distribution of the Sinipercinae fishes. Zoological Res. 1991;26: 40-4 (in Chinese with English abstract).

Li Y, Li J, Lu J, Li Z, Shi S, Liu Z. Effects of live and artificial feeds on the growth, digestion, immunity and intestinal microflora of mandarin fish hybrid (Siniperca chuatsi o+ $\times$ Siniperca scherzeri 31 ). Aquac Res. 2017;48: 4479-85.

Liang XF, Liu JK, Huang BY. The role of sense organs in the feeding behaviour of Chinese perch. J Fish Biol. 1998;52:1058-67.

Madsen L, Petersen RK, Kristiansen K. Regulation of adipocyte differentiation and function by polyunsaturated fatty acids. Biochim Biophys Acta. 2005;1740: 266-86.

Maita M. Fish health assessment. In: Nakagawa H, Sato M, Gatlin III DM, editors. Dietary supplements for the health and quality of cultured fish. Washington, DC: CABI; 2007. p. 10-34.

Mozanzadeh MT, Agh N, Yavari V, Marammazi JG, Mohammadian T, Gisbert E. Partial or total replacement of dietary fish oil with alternative lipid sources in silvery-black porgy (Sparidentex hasta). Aquaculture. 2016:451:232-40.

Nasopoulou C, Zabetakis I. Benefits of fish oil replacement by plant originated oils in compounded fish feeds. A review. LWF-Food Sci Technol. 2012;47: $217-24$.

National Research Council (NRC). Nutrient requirements of fish and shrimp. Washington: National Academies Press; 2011.

Nayak M, Saha A, Pradhan A, Samanta M, Giri SS. Dietary fish oil replacement by linseed oil: effect on growth, nutrient utilization, tissue fatty acid composition and desaturase gene expression in silver barb (Puntius gonionotus) fingerlings. Comp Biochem Physiol B. 2017;205:1-12.

Peng X, Li F, Lin S, Chen Y. Effects of total replacement of fish oil on growth performance, lipid metabolism and antioxidant capacity in tilapia (Oreochromis niloticus). Aquacult Int. 2015;24:145-56.

Ren HT, Yu JH, Xu P, Tang YK. Influence of dietary fatty acids on muscle fatty acid composition and expression levels of $\Delta 6$ desaturase-like and Elovl5-like elongase in common carp (Cyprinus carpio var. Jian). Comp Biochem Physiol B. 2012;163:184-92.

Sankian Z, Khosravi S, Kim YO, Lee SM. Effect of dietary protein and lipid level on growth, feed utilization, and muscle composition in golden mandarin fish Siniperca scherzeri. Fish Aquat Sci 20. 2017. https://doi.org/10.1186/s41240017-0053-0

Sankian Z, Khosravi S, Kim YO, Lee SM. Effects of dietary inclusion of yellow mealworm (Tenebrio molitor) meal on growth performance, feed utilization, body composition, plasma biochemical indices, selected immune parameters and antioxidant enzyme activities of mandarin fish (Siniperca scherzeri) juveniles. Aquaculture. 2018;496:79-87.

Sankian Z, Khosravi S, Kim YO, Lee SM. Dietary protein requirement for juvenile mandarin fish, Siniperca scherzeri. J World Aquacult Soc. 2019;50:34-41.

Sargent JR, Tocher DR, Bell JG. The lipids. In: Halver JE, Hardy RW, editors. Fish nutrition. San Diego, CA: Academy Press; 2002. p. 181-257.

Thanuthong T, Francis DS, Senadheera SD, Jones PL and Turchini GM. 2011. Fish oil replacement in rainbow trout diets and total dietary PUFA content: I) effects on feed efficiency, fat deposition and the efficiency of a finishing strategy. Aquaculture 320, 82-90.

Tocher DR. Fatty acid requirements in ontogeny of marine and freshwater fish. Aquac Res. 2010;41:717-32.

Todorčević M, Kjær MA, Djaković N, Vegusdal A, Torstensen BE, Ruyter B. N-3 HUFAs affect fat deposition, susceptibility to oxidative stress, and apoptosis in Atlantic salmon visceral adipose tissue. Comp Biochem Phys B. 2009;152: 135-143.

Turchini GM, Francis DS. Fatty acid metabolism (desaturation, elongation and beta-oxidation) in rainbow trout fed fish oil- or linseed oil-based diets. $\mathrm{Br} \mathrm{J}$ Nutr. 2009:102:69-81.

Turchini GM, Francis DS, De Silva SS. Fatty acid metabolism in the freshwater fish Murray cod (Maccullochella peelii peelii) deduced by the whole body fatty acid balance method. Comp Biochem Phys B. 2006;144:110-8.

Turchini GM, Francis DS, Senadheera SPSD, Thanuthong T, De Silva SS. Fish oil replacement with different vegetable oils in Murray cod: evidence of an "omega-3 sparing effect" by other dietary fatty acids. Aquaculture. 2011a;315: 250-9.

Turchini GM, Ng WK, Tocher DR. Fish oil replacement and alternative lipid sources in aquaculture feeds. Boca Raton: CRC Press; 2011b.

Twibell RG, Gannam AL, Hyde NM, Holmes JSA, Poole JB. Effects of fish meal- and fish oil-free diets on growth responses and fatty acid composition of juvenile coho salmon (Oncorhynchus kisutch). Aquaculture. 2012;360-361:69-77.

Wu LX, Jiang ZQ, Qin KJ. Feeding habit and fishery utilization of Siniperca scherzeri in Biliuhe reservoir. J Fish Sci Chin. 1997;44:25-9 (in Chinese with English abstract).

Yıldız M, Eroldoğan OT, Ofori-Mensah S, Engin K, Baltacı MA. The effects of fish oil replacement by vegetable oils on growth performance and fatty acid profile of rainbow trout: re-feeding with fish oil finishing diet improved the fatty acid composition. Aquaculture. 2018;488:123-33.

Zhang L, Wang YJ, Hu MH, Fan QX, Cheung SG, Shin PKS, Li H, Cao L. Effects of the timing of initial feeding on growth and survival of spotted mandarin fish Siniperca scherzeri larvae. J Fish Biol. 2009;75:1158-72.

Zhou CW, Yang Q, Cai DL. On the classification and distribution of the Sinipercinae fishes (family Serranidae). Zool Res. 1988;9:113-26 (in Chinese with English abstract).

Zhou L, Han D, Zhu X, Yang Y, Jin J, Xie S. Effects of total replacement of fish oil by pork lard or rapeseed oil and recovery by a fish oil finishing diet on growth, health and fish quality of gibel carp (Carassius auratus gibelio). Aquac Res. 2016:47:2961-75.
Ready to submit your research? Choose BMC and benefit from:

- fast, convenient online submission

- thorough peer review by experienced researchers in your field

- rapid publication on acceptance

- support for research data, including large and complex data types

- gold Open Access which fosters wider collaboration and increased citations

- maximum visibility for your research: over $100 \mathrm{M}$ website views per year

At BMC, research is always in progress.

Learn more biomedcentral.com/submissions 